\title{
CERAMIC MATERIAL POROUS STRUCTURE PREPARED USING PORE-FORMING ADDITIVES
}

\author{
A. Mocciaro, ${ }^{1,3}$ M. B. Lombardi, ${ }^{1,2}$ and A. N. Scian ${ }^{1,2}$
}

Translated from Novye Ogneupory, No. 1, pp. 54 - 57, January, 2017.

Original article submitted November 17, 2016.

Porous ceramic materials exhibit high permeability, specific surface, and thermal shock resistance, and therefore they may be used successfully in the production of filters, membranes, and as a substrate for catalytic reactions, etc. One method for preparing high material porosity is addition of a pore-forming substance. Porosity (open and closed), pore size distribution, their size and shape, depend on the nature, amount, and morphology of pore-forming substance. In this article the effect is elucidated of three different types of carbon additives on porosity of ceramic prepared from clay and chemical binder precursor. Carbon materials are studied in an $\mathrm{x}$-ray diffractometer. Ceramic material properties are studied using a mercury porosimeter, the Archimedes method, scanning electron and optical microscopes, and microcomputer tomography.

Keywords: ceramic materials, porous structure, pore-forming additive, carbon.

\section{INTRODUCTION}

Porous ceramics are used extensively in high-temperature processes due to low thermal conductivity, high permeability, low density, high specific surface, etc. Some fields of their application are filters for molten metal, for treating engine gases, membranes, substrates for catalytic reactions, heat insulation, etc. $[1,2]$. There are several methods for creating porous structures by means of various materials and processes [3-5]. Most often pore-forming additives are introduced in the material composition, such as starch, graphite, and other organic compounds, which decompose and leave cavities in a matrix after heat treatment. The amount of porosity (open or closed), pore size distribution, pore size and shape depend on the nature, amount, and morphology of pore-forming additive. The effect of porous ceramic structure prepared from a mixture of clay and chemical binder precursor of three different types of carbon (charcoal, lamp black, carbon from oil residue) is studied.

1 Centro de Tecnología de Recursos Minerales y Cerámica CETMIC, La-Planta, Argentina.

2 Departmento de Química, Facultad de Ciencias Exactas, Universidad Nacional de La Plata, Argentina.

3 anamocciaro@cetmic.unlp.edu.ar

\section{EXPERIMENTAL PROCEDURE}

\section{Porous ceramic material preparation}

Porous materials were prepared from clay grade Tincar super, a chemical binder precursor, and three different carbon sources: charcoal, lamp black, and carbon from oil residue. These sources of carbon were limited to a size of $70-106 \mu \mathrm{m}$, with the exception lamp black that itself was very finely dispersed material. Bars were prepared in the form of a prism by uniaxial compaction under a pressure of $40 \mathrm{MPa}$. A mixture of clay, $25 \%$ of different forms of carbon, and $10 \%$ chemical binder precursor (whose content depends on amount of clay) was pressed, and then heat treated to $1550^{\circ} \mathrm{C}$ in an electric furnace in an air atmosphere with a heating rate of $5^{\circ} \mathrm{C} / \mathrm{min}$ with holding at this temperature for $2 \mathrm{~h}$.

\section{Analysis of carbon raw material and clay}

Carbon-containing materials were studied by $\mathrm{x}$-ray diffraction by means of a Philips PW-3710 diffractometer in $\mathrm{Cu}$ $K_{\alpha}$-radiation $(\lambda=0.0154 \mathrm{~nm})$ with $40 \mathrm{kV}$ and $20 \mathrm{~mA}$. Specimens were tested after preliminary drying at $110^{\circ} \mathrm{c}$ for $24 \mathrm{~h}$. An $\mathrm{x}$-ray diffraction pattern for carbon raw material is shown in Fig. 1. The width of peaks points to the low crystallinity of carbon. For charcoal there are also sharply defined phases, corresponding to calcium and magnesium carbonates. The 

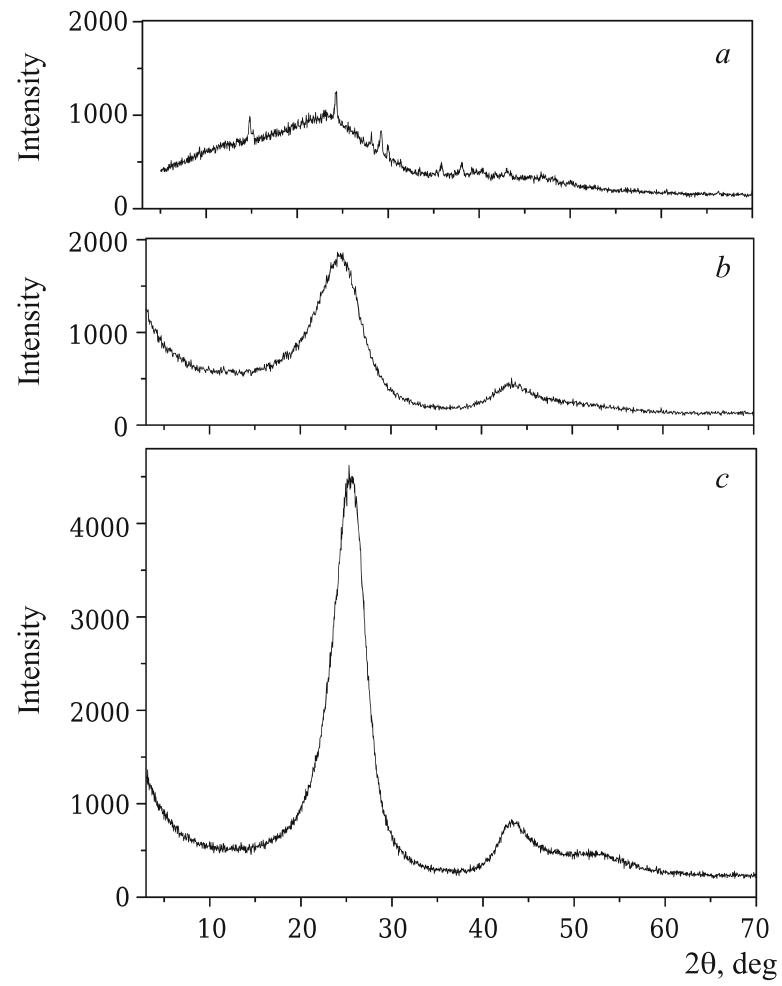

Fig. 1. Carbon raw material x-ray diffraction pattern: a) charcoal; b) lamp black; c) carbon from oil residue.

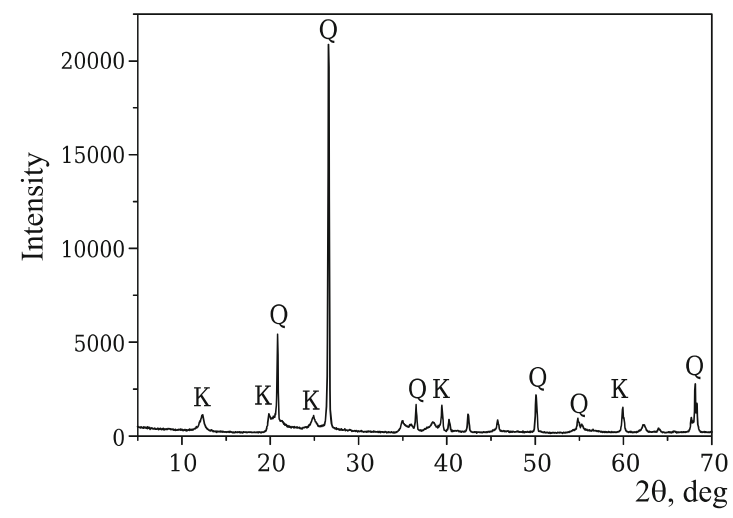

Fig. 2. X-ray diffraction pattern of Tincar super clay grade: $Q$ is quartz; $\mathrm{K}$ is kaolinite.

most crystalline structure is observed for carbon from oil residue. Loss during calcining at $1000^{\circ} \mathrm{C}$ for carbon from oil residue and lamp black comprises $100 \%$, whereas for charcoal this index equals $98.56 \%$. X-ray diffraction was also used to analyze ash and was separated for $\mathrm{CaO}$ and $\mathrm{MgO}$, and the result obtained were compared with those of studying a specimen as a whole.

Clay chemical composition, \%: \%: $\mathrm{SiO}_{2} 65.70, \mathrm{Al}_{2} \mathrm{O}_{3}$ 21.10, $\mathrm{Na}_{2} \mathrm{O}$ 0.07, $\mathrm{K}_{2} \mathrm{O} 0.68, \mathrm{CaO} 0.26, \mathrm{Fe}_{2} \mathrm{O}_{3} 0.85, \mathrm{MgO}$ $0.22, \mathrm{TiO}_{2} 0.43$, balance $2.92, \Delta m_{\text {cal }} 7.77$. An x-ray diffraction pattern for clay is shown in Fig. 2. It may be confirmed that clay grade Tincar super is kaolin clay with a significant quartz content. This type of clay on firing above $1400^{\circ} \mathrm{C}$ is transformed into mullite and cristobalite that are the main crystalline phases.

\section{Porous ceramic research procedure}

Bulk density and open porosity of fired specimens were determined by the Archimedes method in water (by IRAM 12310). True density of ceramic from a mixture of clay and precursor of chemical binder without carbon additive was measured by means of a pycnometer in kerosene (by IRAM 12517) and for a mixture of phases with a specific content of each by the Reitveld method. This method makes it possible to evaluate the amount of crystalline and non-crystalline phases in a specimen from an x-ray diffraction pattern. In order to determine specimen true density it was ground in a Herzog mill to a particle size of less than $44 \mu \mathrm{m}$. Closed porosity was calculated for the materials from true density and open porosity, and material overall porosity was calculated and compared with total porosity obtained by means of an $\mathrm{x}$-ray microtomograph in a Bruker SkyScan 1173 instrument with resolution of $3 \mu \mathrm{m}$.

Open pore size distribution was determined by a mercury method in a PASCAL 440 and 140 porosimeter from Thermo Fisher Scientific. Microstructure was studied in a scanning electron microscope equipped with a JCM-6000 NeoScope, in a Bruker SkyScan 1173 x-ray microtomograph, and by means of an Olympus BX60 optical microscope. Ultimate strength with three-point bending was determined in a JJK, Lemes T22K universal instrument.

\section{RESULTS AND DISCUSSION}

$\mathrm{X}$-ray diffraction patterns for ceramic materials are shown in Fig. 3. The main crystal phases in materials are mullite and cristobalite. Indices of apparent density and apparent density in water (solid substance density including closed pores) of ceramic are provided in Table 1. No differences in ceramic density with additives of different forms of carbon were observed.

Phases existing within ceramic materials without added carbon were determined by the Reitveld method: $35 \%$ cristobalite. $24 \%$ mullite, and $41 \%$ amorphous phase. From these values and indices of theoretical density for each phase (in publications [6-8]) the theoretical density $\delta_{\text {th }}$ of the material was calculated; it appeared to equal $2.46 \mathrm{~g} / \mathrm{cm}^{3}$. True material density without added carbon was determined by means of a pycnometer $\left(\delta_{\mathrm{pyc}}\right)$ and appeared to equal $2.40 \mathrm{~g} / \mathrm{cm}^{3}$. From these density indices closed porosity $P 1$ was determined for material with pore-forming additive.

Open porosity (determined by the Archimedes method), closed porosity calculated by true density (see above), and overall porosity (obtained by x-ray microtomography), and also ultimate strength in three-point bending, are given in Table 2 . Overall porosity with added lamp black appeared to be higher than for materials with other carbon additives. This is 


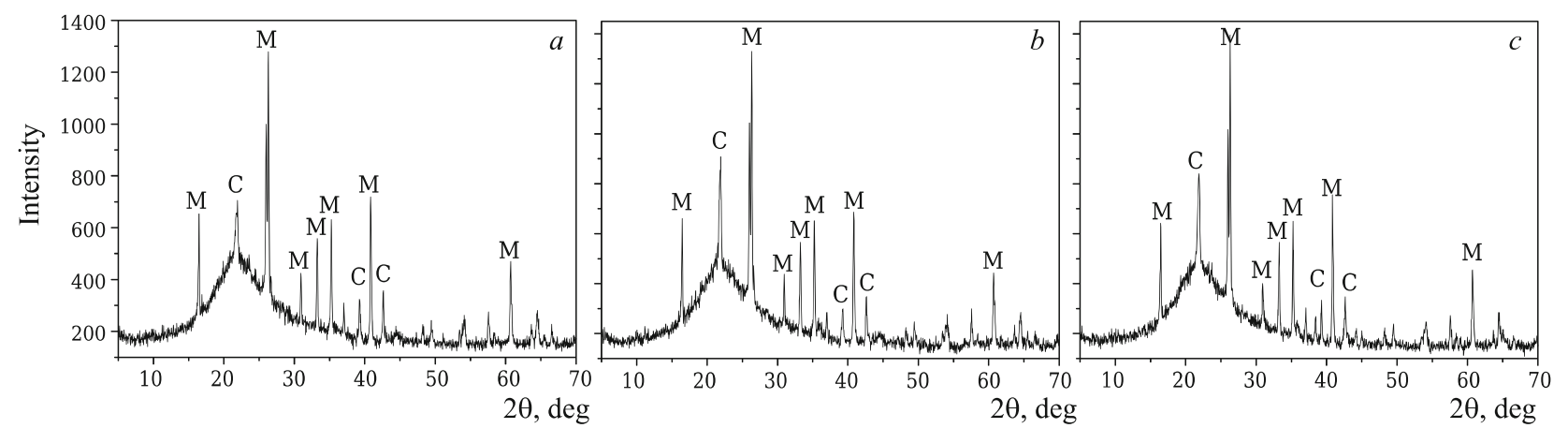

Fig. 3. X-ray diffraction patterns of ceramic material prepared from a mixture with charcoal $(a)$, lamp black $(b)$, oil residue carbon $(c)$ : M is mullite; $\mathrm{C}$ is cristobalite.

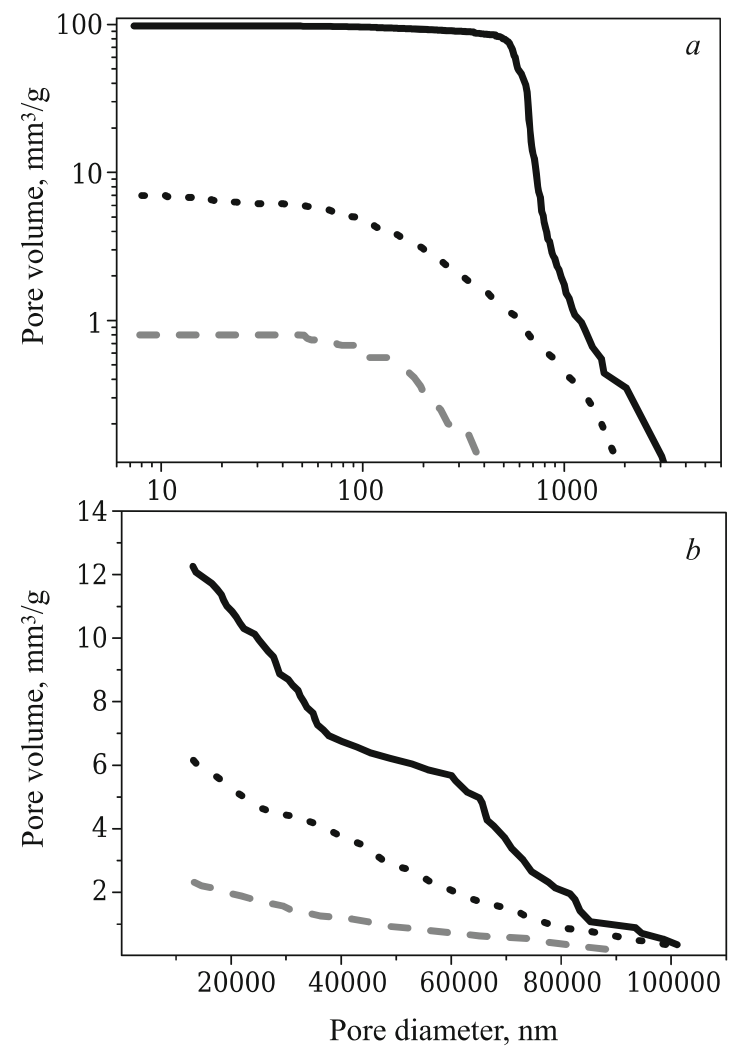

Fig. 4. Pore size distribution from results in a mercury porosimeter for specimens with pore-forming additive: a) mesopores; b) macropores; - $\longrightarrow$ lamp black; $\cdots$ ) oil residue carbon; ---) charcoal.

explained by the grater difference in open porosity index for the material.

Differences are detected between open porosity indices determined in a pycnometer and theoretical density; this is probably explained by errors in pycnometer measurements, and therefore if a specimen was not milled entirely, there could be closed pores within particles or errors were made in determining amorphous phase content, whose density if identical to that of fuzed quartz.
TABLE 1. Ceramic Material Apparent Density

\begin{tabular}{lcc}
\hline \multicolumn{1}{c}{ Carbon type } & $\begin{array}{c}\text { Apparent density, } \\
\mathrm{g} / \mathrm{cm}^{3}\end{array}$ & $\begin{array}{c}\text { Apparent density in water, } \\
\mathrm{g} / \mathrm{cm}^{3}\end{array}$ \\
\hline Charcoal & 2.00 & 2.08 \\
Lamp Black & 1.93 & 2.18 \\
Oil residue carbon & 1.97 & 1.99 \\
\hline
\end{tabular}

Open pore size distribution in materials appeared to be in the range from 3000 to $7 \mathrm{~nm}$ (mesopores, see Fig. $4 a$ ). Pore size with use of lamp black was $500-1100 \mathrm{~nm}$, and pore volume was $100 \mathrm{~mm}^{3} / \mathrm{g}$. This index is much higher than with use of other carbon additives. With use of charcoal in specimens the continuous pore distribution is in the range $40-400 \mathrm{~nm}$, and pore volume is less than $1 \mathrm{~mm}^{3} / \mathrm{g}$. A broader spectrum of pore size is observed with use of carbon from oil residue, i.e., in the range $10-2000 \mathrm{~nm}$, and the overall pore volume $7 \mathrm{~mm}^{3} / \mathrm{g}$. Macropore size distribution $(>10,000 \mathrm{~nm})$ is shown in Fig. $4 b$. As afar as mesopores are concerned, then their greater volume is observed with use of lamp black. A pore size distribution of two types is observed. With use of charcoal and carbon from oil residue a broad scatter of pore sizes arises, and with use of charcoal the pore volume appeared to be very low $\left(2.33 \mathrm{~mm}^{3} / \mathrm{g}\right)$ for all three specimens.

Strength properties given in Table 2 correspond to the index for total porosity, and also pore size distribution (see Fig. 4). Mechanical strength increases as there is a reduction in specimen overall porosity, but a difference is observed between indices for a specimens with lamp black and those with the other two types of carbon, since in a specimen with lamp black there is a greater amount of large size pores.

Overall pore size distribution was studied in a microtomograph (Fig. 5). Pore volume in specimens with lamp black coincided with those obtained with measurement in a mercury porosimeter, which concerns the scatter of micropore size. This indicates that a greater part of pores are open. Conversely, for the other two specimens of charcoal and carbon from oil residue pore volume appeared to be greater than obtained in a mercury porosimeter (macro- 
TABLE 2. Open, Closed, and Total Porosity, and also Ultimate Strength in Bending for Ceramic Prepared by a Different Recipe

\begin{tabular}{lccccc}
\hline \multicolumn{1}{c}{ Carbon type } & Open porosity, \% & Closed porosity $\delta_{\text {pic }}$ & Closed porosity $\delta_{\text {th }}$ & $\begin{array}{c}\text { Total permeability } \\
\text { (microtomography }\end{array}$ & $\begin{array}{c}\text { Ultimate strength in bend- } \\
\text { ing, MPa }\end{array}$ \\
\hline Wood charcoal & 0.76 & 13.33 & 15.45 & 16.42 & 23.24 \\
Lamp black & 13.41 & 9.17 & 11.38 & 20.45 & 15.98 \\
Oil residue carbon & 0.56 & 17.08 & 19.10 & 15.78 & 22.36 \\
\hline
\end{tabular}

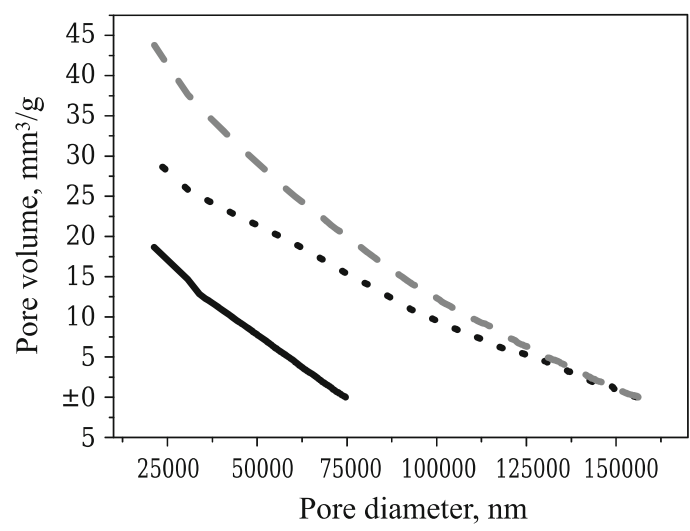

Fig. 5. Research results for specimen pore size distribution in a microtomograph; labelling the same as in Fig. 4.

pores). The difference is explained by closed pores, which agrees with results provided in Table 2 .

Results of studying the microstructure in an x-ray, scanning electron microscope, and optical microscope are shown in Fig. 6. Addition of lamp black as a pore-forming substance gives coarse pores of different shape, and addition of the other two types of carbon gives finer pores uniform with respect to shape. This is probably explained by the size of lamp black particles $(<50 \mathrm{~nm})$ that facilitates formation of lumps and interferes with uniform carbon distribution in a mixture. Divergence is observed between results obtained by different microscopes and by means of a microtomograph, and with results obtained by a porosimeter, which concerns the distribution of macropores with respect to size. Results for distribution of mesopores and macropores with respect to size correspond to density and porosity indices obtained by the Archimedes method.

\section{CONCLUSION}

With use of pore-forming additions it is possible to prepare ceramic materials with different porosity and density less than or equal to $2 \mathrm{~g} / \mathrm{cm}^{3}$. Use of charcoal and carbon from oil residue as an additive gives almost identical results for ceramic overall porosity. Material open porosity prepared with addition of charcoal and carbon from oil residue is less than for material with addition of lamp black. Lamp black facilitates formation of a considerable number of mesopores in greater number than for carbon from other sources. This is

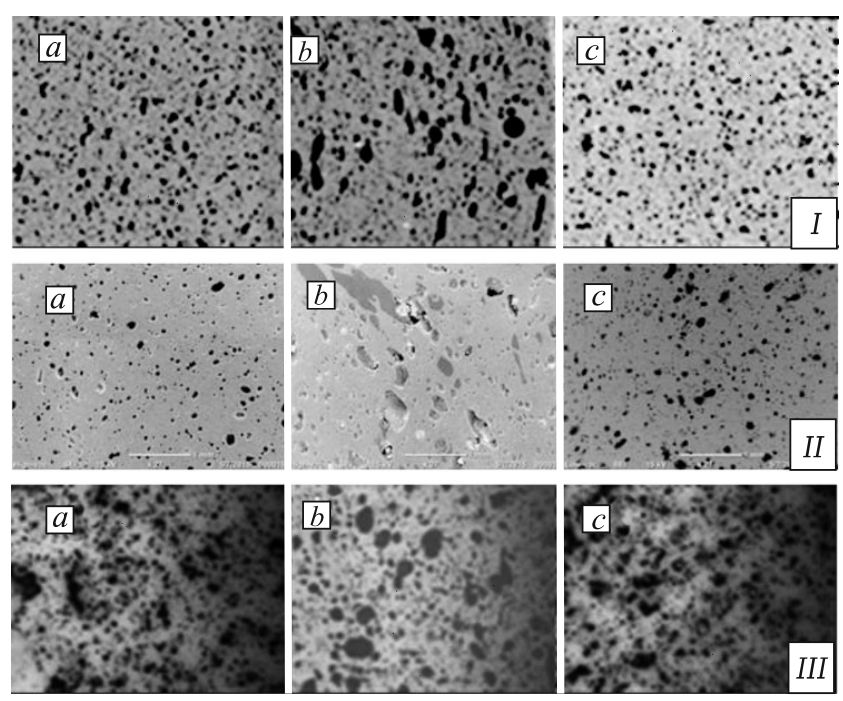

Fig. 6. Microstructure of specimens with additions of wood charcoal $(a)$, lamp black $(b)$, and oil residue carbon $(c)$ obtained in an $\mathrm{x}$-ray mictrotomograph $(I)$, a scanning electron microscope $(\times 27$, $I I)$, and an optical microscope $(\times 40, I I I)$.

explained by the difficulty of dispersing carbon nanoparticles.

\section{REFERENCES}

1. Y. Guzman, "Certain principles of formation of porous ceramic structures. Properties and applications (review)," Glass Ceram., 60, $280-283$ (2003).

2. J. Luyten, S. Mullens, and I. Thijs, "Designing with pores - synthesis and applications," Kona, 28, 131 - 132 (2010).

3. P. Colombo, "Conventional and novel processing methods for cellular ceramics," Philos. Trans. R Soc. A, 364, 109-124 (2006).

4. A. Studart, U. T. Gonzanbach, et al., "Processing routes to macroporous ceramics (review)," J. Amer. Ceram. Soc., 89, No. 6, 1771 - 1789 (2006).

5. F. Tang, H. Fudouzi, et al., "Preparation of porous materials with controlled pore size and porosity," J. Europ. Ceram. Soc., 24, $341-344$ (2004).

6. W. Wong-Ng, H. McMurdie, et al., "Standard x-ray diffraction powder patterns of fourteen ceramic phases," Powder Diffraction, No. 3, 113 - 121 (1988).

7. H. Schneider, J. Schreuer, et al., "Structure and properties of mullite (review)," J. Europ. Ceram. Soc., 28, No. 2, 329-344 (2008).

8. J. E. Shelby, Introduction to Glass Science and Technology; 2nd ed., The Royal Society of Chemistry, Cambridge (2005). 